\title{
Pró-Saúde e PET-Saúde: a Construção da Política Brasileira de Reorientação da Formação Profissional em Saúde
}

\author{
Pró-Saúde and PET-Saúde: Building Brazilian \\ Policy for Health Care Training Reorientation
}

\begin{abstract}
O Programa Nacional de Reorientação da Formação Profissional em Saúde (Pró-Saúde) foi criado a partir do acúmulo construído, ao longo das décadas anteriores, em experiências de integração ensino-serviço e também a partir da avaliação do Promed, primeira iniciativa governamental voltada para apoiar a implementação das Diretrizes Curriculares Nacionais (DCN) em 20 cursos de graduação em Medicina.

Na mesma época em que o Pró-Saúde foi instituído, o Ministério da Saúde, por meio da Secretaria de Gestão do Trabalho e da Educação na Saúde (SGTES), em parceria com o Instituto de Estudos e Pesquisas Educacionais Anísio Teixeira (Inep) e com docentes e pesquisadores vinculados a universidades das diferentes regiões do País, realizou um estudo sobre a aderência dos cursos de graduação às DCN. O estudo teve um recorte que envolveu os cursos de Enfermagem, Medicina e Odontologia. O Promed, que incidira apenas na Medicina, foi ampliado para a Enfermagem e para a Odontologia no Pró-Saúde I em 2006. Eram estas também as profissões inseridas na Estratégia de Saúde da Família. Já o Pró-Saúde II foi estendido, em 2007, para as 14 profissões da área da saúde, seguindo a recomendação do Conselho Nacional de Saúde e o mesmo movimento de criação dos Núcleos de Apoio à Estratégia de Saúde da Família (Nasf), que promoveram a inserção de outros profissionais da saúde na atenção básica no Sistema Único de Saúde (SUS).

O estudo realizado mostrou que embora as DCN, instituídas em 2001 para a Enfermagem e a Medicina e em 2002 para a Odontologia, já estivessem retratadas nos projetos pedagógicos dos cursos de graduação criados após essas datas, a sua implementação ainda não havia se efetuado na prática. Essa observação foi possível de ser identificada a partir da análise dos relatórios de avaliação dos cursos.

Nesse sentido, a implementação do Pró-Saúde I em 89 cursos de graduação das três áreas já citadas, seguido do Pró-Saúde II, que ampliou o seu alcance para toda a área da saúde, abrangendo um total de 359 cursos de graduação, desempenhou um papel importante na efetiva implementação das DCN e também na reorientação da formação, na direção de que o processo de ensino-aprendizagem se dê desde o princípio e ao longo de todo o curso, inserido e articulado com a rede de serviços, com ênfase na atenção básica, na compreensão ampliada dos determinantes sociais no processo de saúde-adoecimento, com ênfase no aprendizado do aluno e no uso das metodologias ativas e na concepção de saúde usuário-centrada.

A análise dos 186 artigos apresentados para publicação nos dois números especiais da Revista Brasileira de Educação Médica (Rbem), somada às centenas de trabalhos sobre o tema que têm sido apresentados em congressos científicos e aos artigos já publicados neste e em outros veículos, evidencia os resultados e as experiências enriquecedoras e singulares que são consequência do amplo engajamento e ação articulada das universidades com os serviços e os gestores do SUS e com os usuários do sistema, por meio da participação dos conselhos de saúde nas Comissões Gestoras Locais de acompanhamento dos projetos do Pró-Saúde.
\end{abstract}


O monitoramento e avaliação do Pró-Saúde e a identificação dos avanços e desafios ainda por ser enfrentados conduziram à criação do Programa de Educação pelo Trabalho em Saúde (PET-Saúde), que teve o objetivo geral coincidente com o Pró-Saúde, mas lançou mão de estratégias complementares, focadas no eixo dos cenários de prática e no processo de ensino-aprendizagem que se dá na rede de serviços, em uma relação que envolve o docente, o estudante, a equipe de saúde do serviço e os usuários do SUS.

Se o Pró-Saúde foi estruturante para promover mudanças institucionais e o deslocamento da área da saúde da universidade, de dentro dos seus muros, para a integração com a comunidade e suas necessidades no SUS, o PET-Saúde reforçou esse movimento, conferindo maior concretude ao processo por meio de projetos diretos de intervenção com base em diagnóstico situacional do território.

O PET-Saúde ajudou a introduzir o componente pesquisa, em especial a pesquisa clínica, a pesquisa-ação, a pesquisa sobre ensino e aprendizagem e sobre a gestão dos serviços da saúde. Esse componente, juntamente com o ensino-aprendizagem incorporados aos serviços e ao processo de trabalho em saúde, tem contribuído decisivamente para qualificar a atenção à saúde prestada, e isso está evidenciado em estudos comparativos já publicados.

No eixo da orientação pedagógica, a formação docente não orientada ao processo de mudanças em curso e a falta de valorização da graduação em relação à pós-graduação na universidade apontaram a necessidade de buscar estratégias que incidissem sobre a pós-graduação e que pudessem também, nesse espaço, legitimar e contribuir para a valorização da graduação.

Assim, como estratégia complementar ao Pró-Saúde e ao PET-Saúde, o Ministério da Saúde, por meio da SGTES em parceria com o Ministério da Educação, a partir da Secretaria de Educação Superior (Sesu), e com a Coordenação de Aperfeiçoamento de Pessoal de Nível Superior (Capes), instituiu o Programa Nacional de Desenvolvimento Docente em Saúde
(Pró-Ensino). O objetivo do Pró-Ensino é promover a formação docente orientada à sustentabilidade do processo de mudanças em curso e fortalecer as linhas de pesquisa relacionadas ao ensino e à graduação.

O trabalho desenvolvido pelo Instituto Regional da Faimer (Foundation for the Advancement of Medical Education and Research) no Brasil, sediado na Universidade Federal do Ceará, com o apoio da SGTES, também vem exercendo um relevante papel na formação de uma rede de docentes em todo o País, capacitados para exercer a liderança na formulação e implementação dos projetos de mudanças no ensino na área da saúde.

O grande número de artigos submetidos para dois números especiais da Rbem reflete o crescimento e amadurecimento dos resultados desses programas e constitui-se uma oportunidade ímpar de registrar e compartilhar a trajetória trilhada, fazendo um balanço, identificando o quanto se avançou e tomando fôlego para prosseguir no enfrentamento dos novos e vultosos desafios que se apresentam pela frente.

Os avanços alcançados não devem nos imobilizar, já que o ponto de chegada coincide com o ponto de uma nova partida. O SUS acaba de regulamentar parte da Lei Orgânica da Saúde, a Lei no 8.080/1990 por meio do Decreto n 7.508/2011. A consolidação do processo de regionalização do SUS, e em cada região da saúde, assim como a consolidação das redes de atenção à saúde, estão na ordem do dia. Indicadores estão sendo criados para que se possa medir o acesso com qualidade à atenção à saúde e o grau de satisfação dos usuários do SUS. E para que isso possa se tornar realidade, não há dúvidas de que os profissionais e trabalhadores da saúde são imprescindíveis.

Ana Estela Haddad Sigisfredo Luiz Brenelli Geraldo Cunha Cury

Rosana Fiorini Puccini Milton de Arruda Martins José Roberto Ferreira Francisco Eduardo de Campos 